\title{
Experiential Marketing as a Tool of Improvement of Competitiveness of Enterprises in the Market of Bread and Bakery Products
}

\author{
Tatiana Litvinova \\ Senior Lecturer of the Department of Management, \\ Volgograd State Agrarian University, Volgograd, Russia \\ Irina Morozova \\ Professor of the Department of World Economy and Economic Theory, \\ Volgograd State Technical University, Volgograd, Russia
}

\section{Stanislav Yatsechko}

Volgograd State Technical University, Volgograd, Russia Krasnoznamenskaya st., 8-71, Volgograd, Russia, 400005

Email: morozovaira@list.ru

\section{Doi:10.5901/mjss.2015.v6n3s6p11}

\begin{abstract}
The article studied the Russian market of bread and bakery products. In order to determine the organoleptic properties of bread and bread products a 5-point rating scale was designed. On the basis of the developed method we carried out an organoleptic evaluation of well-known types of Russian bread: Barskiy, Trapeznyy, Appetitnyy, Grozd and Izyskannyy by a 5-point scale, and on this basis the radar chart was built. While determining the degree of superiority of one product over another under those conditions, in which operation or use of the goods by the consumer is realized, one use the method qualimetric assessment that allows getting indicator of quality in the form of a numeric value. While determining the degree of superiority of one product over another under those conditions, in which operation or use of goods by consumer, method of qualimetric assessment is used, which allows getting quality indicator in the form of a numeric value. In order to provide an objective assessment of the quality of a product it is necessary to formalize the criteria of quality that is to present them in a form of an array of digital data. Then the authors performed a calculation of the integral index of competitiveness of bread and bread products. During the process of research the authors conclude that the high quality of product is not enough for it to be in demand by consumers. Consequently, during calculation of the integral index of relative competitiveness of the samples of bread under research it is necessary to divide the indicators of quality into groups: functional, aesthetic, economic and marketing. In this example, use of experiential marketing in promotion of Appetitnyy bread will allow improving its competitiveness up to 0.80 and making it the most competitive one among the products under research.
\end{abstract}

Keywords: competitiveness of enterprise, experiential marketing, the market of bread and bakery products.

\section{Introduction}

Experiential marketing is a modern and effective tool of improving competitiveness of enterprises in the market of bread and bakery products, as it provides loyalty of consumers to bread or bakery products and its manufacturer not at the cost of qualities of bread, change of which requires significant expenses for manufacturer, but at the cost of marketing that requires significantly less expenses. Consequently, experiential marketing allows not only improving competitiveness of a company in the market of bread and bakery products, but also increasing its revenue and profitability.

In the Russian market of bread and bakery products under the condition of transition from a command to a market economy, a number of structural changes have occurred. Competition from the side of numerous mini-bakeries, obsolete equipment and lack of experience of operation under the conditions of market economy became an impetus for modernization of enterprises, manufacture of high-quality products, expanse of the range, creation of own distribution networks and customer services at the contemporary level.

Some enterprises have introduced the technology of producing bread and bakery products in a half-baked state using technology of deep vacuuming. Volumes of manufacturing such products are small now, but they are in demand. 
Supermarket chains - potential consumers of bread products - actively develop. In Russia, there is an increasing demand for multi-component bread products with a complex formulation, manufacture of which requires use of manual labor. Intense competition in the market encourages manufacturers of bread and bread products to find new effective tools for promotion and marketing. Such a tool is impression marketing.

\section{Specialization}

Subject area of research is constituted by the Russian market of bread and bakery products.

\section{Methods and Techniques}

This research uses the author's method of assessing competitiveness of enterprises in the market of bread and bakery products. According to this method, competitiveness of a company is determined by competitiveness of their products. In order to determine the organoleptic properties of bread and bread products a 5-point rating scale was designed (Table. 1).

Table 1. 5-point scale of organoleptic assessment of bread and bread products

\begin{tabular}{|c|c|c|}
\hline Indicator & Point & Characteristics \\
\hline \multirow[t]{5}{*}{ Appearance: form } & 5 & Regular, square or oval, not squeezed, not runny \\
\hline & 4 & Regular with slight smashes \\
\hline & 3 & Slightly smashed and runny \\
\hline & 2 & Runny, with side growths \\
\hline & 1 & Irregular form, runny, smashed \\
\hline \multirow[t]{5}{*}{ Surface } & 5 & Smooth or slightly rough, without injuries \\
\hline & 4 & Smooth, rough, floury \\
\hline & 3 & Smooth with slight rugosity \\
\hline & 2 & Rugose, floury, with cracks \\
\hline & 1 & Very rough with big cracks and injuries \\
\hline \multirow[t]{5}{*}{ Colour } & 5 & Light-brown, peculiar to this kind of bakery products \\
\hline & 4 & Light with brownish shade \\
\hline & 3 & Light with grayish shade \\
\hline & 2 & Light, not peculiar to this kind of bakery products \\
\hline & 1 & Colourless \\
\hline \multirow[t]{5}{*}{ Taste } & 5 & Sweetish, peculiar to this kind of bakery products, without off flavour \\
\hline & 4 & Not sweet, without off flavour \\
\hline & 3 & Tasteless, with slight sourish flavour \\
\hline & 2 & Sourish, not peculiar to this kind of bakery products with slight off after-taste \\
\hline & 1 & Very sour or unleavened, with off after-taste \\
\hline \multirow[t]{5}{*}{ Smell } & 5 & Distinctive, peculiar to this kind of product, without off-aroma \\
\hline & 4 & Distinctive enough, peculiar to this kind of product \\
\hline & 3 & Not distinctive, with off sourish aroma \\
\hline & 2 & Off \\
\hline & 1 & Off, not peculiar to bread product \\
\hline
\end{tabular}

On the basis of the developed method an organoleptic assessment of well-known Russian types of bread Barskiy, Trapeznyy, Appetitnyy, Grozd and Izyskannyy was carried out by a 5-point scale, and on this basis a radar diagram was built (Fig. 1). 


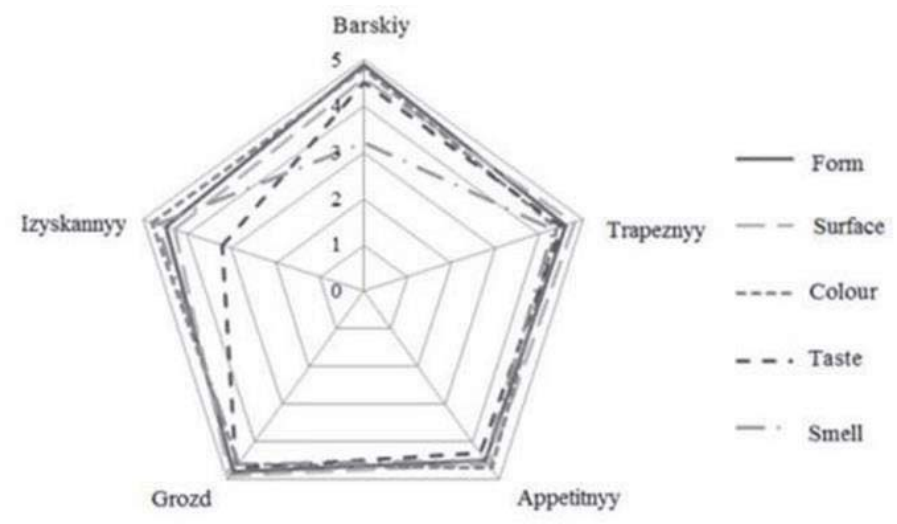

Figure 1. Radar diagram of organoleptic characteristics of bread quality

As it can be seen from Fig. 1, the most pentagonal "petal" belongs to bread Grozd, which is an evidence of received high tasting ratings for all indicators. The other samples received high enough ratings except bread Izyskannyy (taste - 3.2 points) and Barskiy (smell - 3.2 points).

The process of forming competitiveness of products at the enterprises of the baking industry under the contemporary market conditions consists of two interconnected parts: the first one is oriented towards the internal environment from the point of view of optimal organization of production and is described by a sequential list of steps in accordance with the product life cycle; the second is directed to the external environment and outlines by the functions of managing competitiveness of products (Lendermann, 2013).

Under the conditions of market economy, competitiveness of goods is the main factor in the success of an enterprise. It assumes the optimum combination of quality, price, design and opportunity of after-sales service. Competitiveness is a comparative characteristic of goods containing a comprehensive assessment of the totality of industrial, commercial, organizational and economic indicators relatively to the revealed market requirements or features of another product. Competitiveness of the product under research is determined in accordance with other products and always specifically, based on the degree of satisfaction to demands of potential buyers.

While determining the degree of superiority of one product over another under those conditions in which consumer carries out operation or use of the good, the method of qualimetric assessment is used which allows getting indicator of quality in the form of a numeric value. In order to provide an objective assessment of the quality of goods it is necessary to formalize the criteria of quality that means to present them in the form of an array of digital data.

According to the results of qualimetric assessment bread Grozd appeared to be the best sample, integral quality index value of which is equal to 0.75 . All other samples had lower values (Table. 2).

Table 2. Calculation of the integral index of competitiveness of bread and bread products

\begin{tabular}{|c|c|c|c|c|c|c|c|c|c|c|c|c|c|}
\hline \multirow{2}{*}{ Indicator } & \multirow{2}{*}{ A(i) } & \multirow{2}{*}{$\mathrm{Pi}$} & \multirow{2}{*}{$\mathrm{pi}$} & \multicolumn{2}{|c|}{ Barskiy } & \multicolumn{2}{|c|}{ Trapeznyy } & \multicolumn{2}{|c|}{ Appetitnyy } & \multicolumn{2}{|c|}{ Grozd } & \multicolumn{2}{|c|}{ Izyskannyy } \\
\hline & & & & $\mathrm{Pi}$ & $\mathrm{pi}$ & $\mathrm{Pi}$ & pi & $\mathrm{Pi}$ & $\mathrm{pi}$ & $\mathrm{Pi}$ & $\mathrm{pi}$ & $\mathrm{Pi}$ & $\mathrm{pi}$ \\
\hline Form, points & 0.15 & 5.00 & 3.00 & 4.50 & 0.75 & 4.50 & 0.75 & 3.80 & 0.40 & 4.30 & 0.65 & 4.30 & 0.65 \\
\hline Surface, points & 0.15 & 5.00 & 3.00 & 4.40 & 0.70 & 3.00 & 0.00 & 4.40 & 0.70 & 4.30 & 0.65 & 4.20 & 0.60 \\
\hline Colour, points & 0.10 & 5.00 & 3.00 & 4.20 & 0.60 & 4.50 & 0.75 & 4.20 & 0.60 & 4.40 & 0.70 & 3.90 & 0.45 \\
\hline State of crumb, points & 0.05 & 5.00 & 3.00 & 4.50 & 0.75 & 3.10 & 0.05 & 4.10 & 0.55 & 4.70 & 0.85 & 4.50 & 0.75 \\
\hline Taste, points & 0.20 & 5.00 & 3.00 & 3.50 & 0.25 & 4.50 & 0.75 & 4.00 & 0.50 & 4.30 & 0.65 & 4.00 & 0.50 \\
\hline Smell, points & 0.15 & 5.00 & 3.00 & 4.40 & 0.70 & 4.60 & 0.80 & 3.40 & 0.20 & 4.10 & 0.55 & 4.60 & 0.80 \\
\hline Humidity, \% & 0.01 & 49.00 & 52.00 & 46.20 & 1.93 & 47.90 & 1.37 & 47.80 & 1.40 & 48.80 & 1.07 & 47.40 & 1.53 \\
\hline Acidity, degrees & 0.02 & 11.00 & 12.00 & 9.50 & 2.50 & 9.30 & 2.70 & 10.10 & 1.90 & 9.30 & 2.70 & 9.90 & 2.10 \\
\hline Porosity, \% & 0.05 & 50.00 & 46.00 & 55.60 & 2.40 & 52.30 & 1.58 & 54.70 & 2.18 & 52.80 & 1.70 & 50.30 & 1.08 \\
\hline Packing, points & 0.10 & 5.00 & 3.00 & 3.00 & 0.00 & 3.00 & 0.00 & 4.00 & 0.50 & 4.10 & 0.55 & 3.00 & 0.00 \\
\hline Integral indicator & 1,00 & & & 0,7 & & 0,6 & & 0,5 & & 0,7 & & 0,6 & \\
\hline
\end{tabular}

It is known that high quality of a product is not enough to ensure that it is in demand of consumers. Nomenclature of indices for determining competitiveness is somewhat broader, as quality is just one of its components. The indicators 
which provide competitiveness include functionality at product distribution and at proper use (food, biological, energy value, conservability); efficiency of production and product distribution (cost price, price of consumption); aesthetics according to expert evaluation (Morozova, 2006).

Therefore, while calculating the integral indicator of the relative competitiveness of the samples of bread under research it is necessary to divide indicators of quality into the following groups: functional, aesthetic, economic and marketing. Since according to the integral indicator of quality bread Grozd obtained high rating, while determining competitiveness we consider it to be basic and all other samples - competing.

The results of the research show that only bread Trapeznyy has low competitiveness in comparison with Grozd and bakery products Appetitnyy, Izyskannyy and Barskyy have competitive advantages over the basic sample. This can be explained by the fact that the bread Grozd appeared on the market the first of the samples under research of the new range of rye-wheat products, and the other products were developed in accordance with traditional formulations and technologies.

Use of experiential marketing can improve competitiveness of any kind of bread and bakery products, as it increases consumer interest in purchase of it. In this example, use of experiential marketing in promotion of bread Appetitnyy will allow increasing its competitiveness up to 0.80 and making it the most competitive among the products under research.

\section{Results}

One of the modern concepts of marketing management and a way of increasing competitiveness is experiential marketing. Emergence of this concept is the consequence of development of the market, the economy and competition. It is one of the promising directions in development of marketing in general. Consumer behavior depends on big number of factors. Assessing goods, consumer compares its numerous characteristics among themselves, but the decision to buy often puts off to the future. This happens because the good does not attract them, they do not hope to get impressed by it, although they as a potential buyer are satisfied with all qualities of the production.

That is why, the need in experiences while making decisions on purchasing a product can be decisive. In addition, consumers are thinking not only rationally. Very often this process has an emotional nature. There is an impact on the emotional component of the views of a consumer, building a strong emotional connection between goods (trademarks) and consumer is the task of manufacturer and experiential marketing.

The modern market has already understood that to develop and to offer to consumer 'just goods' or 'just services' is not enough: firstly, they do not serve as the main source of profit, and secondly, are not the decisive factor, which determines the purchase. For a company it is important to know that it produces and sells goods and services, which are analogues of an impression, that in the future they may become the basis of its competitive advantage in the market.

Let us define the difference between a product or a service and an experience. Impressions as a product have some specific features: they are imperceptible, they are impossible to prepare in advance, they are very personal. Appearance of the concept of experiential marketing corresponds to the theory of hierarchy of needs of A. Maslow. Have satisfied their numerous needs (physiological, needs for security, social, self-esteem and self-actualization), consumer still wants more impressions. Impressions are the highest degree of the hierarchy.

Modern advertising has accustomed us to the fact that we do buy a not mattress, but a thing that gives us an opportunity 'correct' the shape and to keep the spine in healthy state, not candies, but 'heavenly pleasure', not an electric stove, but a 'miracle oven' etc. Thereby, we are in advance offered those impressions which, in the opinion of companies, we can be interested in and which can attract our attention, can make a desire to possess them in order to achieve certain pleasure and to be delighted with them. Manufacturers stimulate our desire to experience something new, unknown, in order to initiate further purchases. But we should not forget that the impression is mostly often the result of influence of marketing tools on the subconscious of consumer.

Competitiveness of the enterprises of the food industry reflects their flexibility and adaptability to the constant changes of the external environment, and their ability to use available internal resources effectively. Under the conditions of qualitative changes within the global economy caused by increase of competition at all its levels, intensive development, modernization and efficient management by the enterprises of the food industry becomes the pledge of high competitiveness of the country. In order to provide competitiveness of the food enterprises it is necessary to investigate the factors which considerably influence them.

As the factors of competitiveness of the enterprises of the food industry one understands phenomena or processes of production and economic activity and external environment of a food enterprise, presence of which is necessary and sufficient to change the criteria of its competitiveness (quality of production, cost of its production, image of the company, 
etc.), and hence and the level of competitiveness of the enterprise in whole. In essence, the factor of competitiveness of an enterprise is a particular component of its marketing environment which it surpasses the competing enterprises in.

It is obvious that it is impossible to use the list of factors, determining competitiveness of an enterprise by various investigators for enterprises of the food industry in the pure form due to the specificity of this industry. However, one of the main approaches that can be taken into consideration is the approach to grouping factors of increase of competitiveness of enterprises, depending on their impact on driving competitive forces that determine profitability of the industry.

Competitiveness of the food enterprises is affected by many factors, both positive and negative. Identification of these factors, as well as assessment of their influence on competitiveness of enterprises will allow determining of the existing reserves and to form the main directions of improving competitiveness.

In order to determine the totality of factors affecting competitiveness of enterprises, we conducted a research on the market of the baking industry, the first phase of which was directed at identification of these factors and their classification.

Nowadays there is no clear classification of factors of competitiveness of food enterprises. It is proposed to divide factors into internal and external. The internal include objective circumstances that define the opportunities of the company to provide its competitiveness, external - socio-economic and organizational conditions that allow the enterprise to create production that is more attractive by the price and the non-price characteristics (Morozova and Litvinova, 2013).

Scientific methodology of forming competitiveness of the enterprise of the baking industry provides systematization of prerequisites of its achieving: presence of resource support (human, raw materials, financial resources), influence of relation of supply and demand on the assortment of bread and bakery products, observance of the priorities in production and economy activity, foresights of force majeure circumstances and factors of changes of market environment: subjective, regulatory and permanent, which somehow affect increase or decrease of competitive advantages (Popkova, Chashchin and Bogdanov, 2013).

In general case, the prerequisites determines the factors of formation of competitive baking manufacture, which in turn are divided into macro-level factors (economic, organizational and legal, material-technical (raw material) and geographical, scientific and technological (innovation), technological, demographic, social, socio-cultural); meso-level factors (competitiveness of the industry and the region, development of sectoral and regional infrastructure, availability of natural resources, barriers of socio-economic development, the level of 'barriers of exit' from the industry, the level of 'barriers of entry' in the industry); micro-level factors, among which it is necessary to mention, such as emergence of new competitors and behaviour of the existing, behaviour of suppliers, customer behaviour, presence of substitute products, regional management, information and personnel support.

On the basis of analysis of the economic literature and data of express-poll of experts in the baking industry the following classification of factors of competitiveness of bakeries was developed.

I. Internal factors.

1. Raw material resources of an enterprise:

- Availability of limitation of qualitative raw material resources of an enterprise;

- Type of resource, cost and availability of resource;

- The market share of an enterprise as a productive unit.

2. Financial and economic condition of an enterprise:

- Size of the profit;

- Volume of commodity food products in tons and hryvnias;

- Value of own circulating assets of an enterprise;

- Volume of recycled materials in tons and hryvnias;

- Coefficient of financial stability.

3. Productive potential of an enterprise:

- Optimal amount and type of technologies, their age;

- Presence of own processing facilities;

- Degree of using production capacities;

- Degree of deterioration of BPA;

- Structure and cost of BPA;

- Coefficient of disposals and update of BPA.

4. Labour potential of an enterprise:

- Structure and qualifications of personnel;

- Number of personnel. 
5. Marketing potential of an enterprise:

- Availability of marketing service;

- Availability of information and regulatory-methodical basis of management;

- Image of an enterprise;

- Sales possibilities of expanding geographic boundaries of the market;

- Presence of extensive marketing system;

- Quality of products.

6. Investing potential of an enterprise:

- Ability of favourable attracting of external financial resources;

- Amount of internal source of financing (retained profit and depreciation charges).

7. Research and innovative potential

- Number of research-and-production personnel at an enterprise;

- Expenditures on researches, developments and technological innovations;

- Availability of cooperation with academic departments.

8. Territorial and geographical position of an enterprise:

- Access to raw material resources;

- Access to transport networks.

II. External factors.

1. Legal regulation of the functioning of economy of the country:

- The legal system of state management in the sphere of production and realization of bakery products (state regulation of pricing of social kinds of bread);

- Licensing;

- Patenting;

- Certification;

- State support of domestic enterprises of the baking industry.

2. Infrastructure of bakery products:

- Manufacture of services of communication and transport;

- Number of credit and insurance institutions;

- Presence of large number of distributors;

- Presence of service on maintenance of fixed assets.

3. Conditions of demand in the domestic and foreign markets:

- Level of competition in the industry;

- Type and capacity of separate sale markets;

- Barriers at the internal and external markets;

- Average consumption of bakery products per capita;

- Share of bakery products in the structure of consumer spending of the population on food.

- Presence and operation of retail trade.

4. Labour resources of the baking industry:

- Average number of employees of the baking industry;

- Specific weight of workers of the baking industry in total number of employees in the industry of the country;

- Number of specialists-graduates of high schools and institutions of higher education of the corresponding profile.

Determining the degree of influence of mentioned-above factors on competitiveness of enterprises of the baking industry is related to a range of methodological problems of assessment, processing and interpretation of information.

The results of the first phase of the study allowed us to accept the hypothesis, according to which the factors affecting competitiveness of enterprises, are described and measured by a totality of statistical (quantitative) and expert (qualitative) indicators (Nganje et. Al., 2013). At the second stage of the study an analysis of the factors of competitiveness bakeries was performed by ranking them by 1-point system with the use of the method of expert evaluations (leading experts working in the field of bakery and leading scientists, conducting researches in it, were chosen to be experts).

In order to determine the rating of any factor, an individual indicators (depending on the assessment of the expert) is assigned a score. And factor, estimated at 1 point, has the greatest impact on competitiveness of enterprises, and at point 0.1 - the minimal. The results of assessment of factors of competitiveness of enterprises of the baking industry are 
given in Table. 3.

Table 3. Coefficients of weight of factors affecting competitiveness of enterprises of the baking industry

\begin{tabular}{|c|c|c|c|c|c|c|c|c|c|}
\hline \multirow{2}{*}{ Factors of competitiveness } & \multicolumn{7}{|c|}{ Expert } & \multicolumn{2}{|c|}{ Average coefficient of weight } \\
\hline & 1 & 2 & 3 & 4 & 5 & 6 & 7 & 8 & \\
\hline \multicolumn{10}{|l|}{ Internal } \\
\hline Resource potential & 0,14 & 0,22 & 0,07 & 0,14 & 0,21 & 0,22 & 0,19 & 0,16 & 0,17 \\
\hline Productive potential & 0,18 & 0,13 & 0,25 & 0,14 & 0,11 & 0,11 & 0,12 & 0,14 & 0,15 \\
\hline Investing potential & 0,18 & 0,13 & 0,10 & 0,11 & 0,07 & 0,17 & 0,15 & 0,12 & 0,13 \\
\hline Financial-economic position & 0,18 & 0,09 & 0,20 & 0.14 & 0,15 & 0,17 & 0,19 & 0,10 & 0,15 \\
\hline Scientific-innovative potential & 0,09 & 0,13 & 0,05 & 0,14 & 0,04 & 0,07 & 0,10 & 0,15 & 0,10 \\
\hline Staff potential & 0,09 & 0,09 & 0,18 & 0,13 & 0,17 & 0,17 & 0,10 & 0,14 & 0,13 \\
\hline Marketing potential & 0,09 & 0,17 & 0,12 & 0,11 & 0,21 & 0,07 & 0,13 & 0,16 & 0,13 \\
\hline Territory geographical potential & 0,05 & 0,04 & 0,03 & 0,09 & 0,04 & 0,02 & 0.02 & 0,04 & 0,04 \\
\hline Total & 1,00 & 1,00 & 1,00 & 1,00 & 1,00 & 1,00 & 1,00 & 1,00 & 1,00 \\
\hline \multicolumn{10}{|l|}{ External } \\
\hline Legal regulating of functioning of economy & 0,22 & 0,27 & 0,15 & 0,19 & 0,24 & 0,22 & 0,29 & 0,23 & 0,23 \\
\hline Infrastructure of the market of bakery production & 0,33 & 0,33 & 0,32 & 0,23 & 0,2 & 0,31 & 0,18 & 0,32 & 0,28 \\
\hline Demand in the internal and the external markets & 0,35 & 0,2 & 0,42 & 0,43 & 0,38 & 0,34 & 0,32 & 0,33 & 0,35 \\
\hline Labour resources of baking industry & 0,1 & 0,2 & 0,11 & 0,15 & 0,18 & 0,13 & 0,21 & 0,12 & 0,15 \\
\hline Total & 1,00 & 1,00 & 1,00 & 1,00 & 1,00 & 1,00 & 1,00 & 1,00 & 1,00 \\
\hline
\end{tabular}

According to Table. 3 it becomes obvious that the raw resources and demand conditions in the market are the most influential factors, determining competitiveness of enterprises of the baking industry. Therefore, while planning their economic activity, enterprise should pay attention to the demand, prevailing in the market of bakery products and availability of resources in the market. One of the most important factors of competitiveness of enterprises in the market of bread and bakery products is marketing in whole and experiential marketing in particular.

\section{Discussion}

Thereby, experiential marketingis a phenomenon, which is not artificial, it assumes logical development of modern marketing. Experiential marketing sets as an aim organization of such communications to make consumers feel an emotional connection between them and the trademark (brand). Many items (Rafaello sweets, Jacobs coffee, Danon brand dairy products, etc.) would not have become so well-known to consumer, but for the emotions, which are incorporated into these brands. They allow these goods being sold at prices much higher than the cost of their manufacture (Smith and Wheeler 2012)

Experiential marketing appeals to senses and emotions. Emotional people are more amenable to influence, positively evaluate their attitude towards the brand, are proud of the fact that they may be the owner of product, rejoice from the process of its consumption. Producers of goods and services should take all this into account that consumers would reach the maximum enjoyment from their products and would be delighted by the fact that they have it. Experiential marketing directs companies at the fact that they should produce not goods, but experiences. And when the feelings and experiences of a human would occupy a central place in the economic activity of a company, then it can be successful.

\section{Conclusion}

In the result of assessment of competitiveness of five samples of rye-wheat bread, they were determined to be competitive in the market of Russia and to have their consumers. To further improvement of competitiveness of bakery products under the modern conditions not as updating of the material and technical base of enterprises, introduction of advanced technologies, expansion of the sphere of application of modern equipment, completeness of loading of available productive capacity and reduction of costs is needed, but use of effective marketing tools, which include impression marketing.

Experiential marketing is a modern and effective tool of improving competitiveness of enterprises in the market of bread and bakery products, as it provides the consumer loyalty to bread or bakery products and to its manufacturer not at the cost of the qualities of bread, change of which requires significant expenses of manufacturer, but due to marketing that requires significantly less expenses. Consequently, experiential marketingallows not only to improve competitiveness 
of a company in the market of bread and bakery products, but also to increase its revenue and increase profitability.

\section{References}

Lendermann, M. (2013). Experience the Message: How experiential marketing is changing the brand world, Basic Books, New York.

Morozova, I.A. (2006). Issue of improving competitiveness of Russia's transport system and its integration into international transport system. Izvestiya of VolgGTU (News of Volgograd State Technical University). Series "Current issues of reforming Russian economics (theory, practice, perspective)": Collection of scientific articles. Volgograd State Technical University, 6 (11): 73-77.

Morozova, I.A. and T.N. Litvinova. (2013). Major aspects of forecasting entrepreneurial business on the agricultural equipment market. Audit and Financial Analysis. 3 (1): 404-408.

Nganje, W., Kaitibie, S., Wachenhiem, C., Acquah, ET, Matson J. and Johnson G. (2012). Estimating Price Premiums for Breads Marketed as "LowCarbohydrate Breads". Journal of Food Distribution Research. 39 (2): 66-76.

Popkova, E.G., Chashchin, V.V. and Bogdanov, D.V. (2013). Implementation of the Concept of Personnel Marketing In Modern Russia. World Applied Sciences Journal. 22 (3): 389-395.

Smith, S. and Wheeler, J. (2012). Managing the Customer Experience: Turning customers into advocates, FT Press, London. 